\title{
A CIÊNCIA E A TECNOLOGIA NOS INSTITUTOS FEDERAIS E SEU POTENCIAL TRANSFORMADOR: UM BREVE DIÁLOGO COM ÁLVARO VIEIRA PINTO (E O MATERIALISMO HISTÓRICO-DIALÉTICO)
}

\section{Resumo}

0 presente trabalho apresenta um breve ensaio a respeito da compreensão da concepção e diretrizes dos institutos federais, instituições públicas de educação profissional e tecnológica do país, a partir da perspectiva da filosofia da técnica desenvolvida por Álvaro Vieira Pinto, na obra "O Conceito de Tecnologia", por meio da categoria central de análise Trabalho em suas dimensões ontológica e histórica. A partir dos conceitos de tecnologia e razão técnica e sua relação dialética com a produção da existência material humana realizam-se inferências quanto ao potencial revolucionário da formação tecnológica pretendida pelos institutos federais, ao tomar o trabalho como princípio educativo, assim como a pesquisa como princípio pedagógico e científico, na contribuição ao processo de tomada de consciência para si dos/as estudantes trabalhadores/as nestas instituições.

Palavras-chave: Tecnologia. Formação Tecnológica. Institutos Federais. Vieira Pinto.

\section{SCIENCE AND TECHNOLOGY IN FEDERAL INSTITUTES AND ITS TRANSFORMING POTENTIAL: A BRIEF DIALOGUE WITH ÁLVARO VIEIRA PINTO (AND HISTORICAL-DIALETIC MATERIALISM)}

\section{Abstract}

This work presents a brief essay on understanding the conception and guidelines of federal institutes, public institutions of professional and technological education in the country, from the perspective of the philosophy of technique developed by Álvaro Vieira Pinto, in the work "The Concept of Technology ", Through the central category of work analysis in its ontological and historical dimensions. From the concepts of technology and technical reason and its dialectical relationship with the production of human material existence, inferences are made regarding the revolutionary potential of technological training intended by federal institutes, by taking work as an educational 
principle, as well as research as a principle pedagogical and scientific, in the contribution to the process of raising awareness for themselves of the working students in these institutions.

Keywords: Technology. Technological formation. Federal Institutes. Vieira Pinto.

\section{CIENCIA Y TECNOLOGÍA EN INSTITUTOS FEDERALES Y SU POTENCIAL DE TRANSFORMACIÓN: BREVE DIÁLOGO CON ÁLVARO VIEIRA PINTO (Y MATERIALISMO HISTÓRICO-DIALÉTICO)}

\section{Resumen}

Este trabajo presenta un breve ensayo sobre la comprensión de la concepción y lineamientos de los institutos federales, instituciones públicas de educación profesional y tecnológica en el país, desde la perspectiva de la filosofía de la técnica desarrollada por Álvaro Vieira Pinto, en la obra "El Concepto de Tecnología", A través de la categoría central de análisis del trabajo en sus dimensiones ontológica e histórica. A partir de los conceptos de tecnología y razón técnica y su relación dialéctica con la producción de la existencia material humana, se hacen inferencias sobre el potencial revolucionario de la formación tecnológica que pretenden los institutos federales, tomando el trabajo como principio educativo, así como la investigación como principio. pedagógica y científica, en la contribución al proceso de sensibilización de los estudiantes que trabajan en estas instituciones.

Palabras clave: Tecnología. Formación tecnológica. Institutos Federales. Vieira Pinto.

\section{Introdução}

A ampliação do direito à educação por meio da expansão da escolaridade, em todos os níveis, é elemento indispensável na luta pela superação das desigualdades e da exclusão, ocupando posição destacada na promoção de um modelo de desenvolvimento com justiça social.

Para a consecução dessa ampliação, faz-se necessário a efetivação de políticas públicas que elevem a educação à condição de direito essencial para a construção da cidadania. No entanto, cabe salientar que essa discussão remete para a questão de um projeto de nação, onde as conexões possíveis da instituição educacional com o desenvolvimento têm de ser encaradas como matéria de política educacional e cultural com ênfase na produção 
original do saber na perspectiva da passagem de um estado de dependência econômica e cultural para um estado de autonomia, no mínimo relativa.

Na perspectiva progressista, busca-se uma proposta de educação que possibilite a geração de conhecimentos a partir de uma prática interativa com a realidade e a favor do desenvolvimento autônomo nos marcos da civilização baseada na ciência e na tecnologia científica.

$\mathrm{Na}$ atual perspectiva de crise, a excelência do texto de Álvaro Vieira Pinto (2005) em "O Conceito de Tecnologia" e a necessária discussão contemporânea sobre Ciência e Desenvolvimento estabelecem um nexo para a temática das políticas de desenvolvimento ao trazer a contribuição de um dos maiores filósofos brasileiros em seu trabalho de "dissecação" do conceito de tecnologia e da análise teleológica do surgimento da chamada razão técnica, asseverando a real compreensão do uso da tecnologia/técnica no curso da história por meio do pensamento dialético, apresentando de forma irrefutável que o caráter social do ser humano consiste na necessidade de operar em conjunto sobre a natureza para extrair dela os meios de sobrevivência (trabalho portanto, em suas dimensões ontológica e histórica). Tal atividade, enfatiza o autor, é impossível de ser executada senão com alguma espécie de técnica, identificando aí o processo de hominização sob o exercício da razão, em seus diversos estágios.

Neste sentido, procuraremos desenvolver a articulação trabalhociência-tecnologia-cultura na concepção e diretrizes dos Institutos Federais e sua aproximação com o pensamento de Álvaro Vieira Pinto a partir da obra "O Conceito de Tecnologia", Volume I e os pressupostos do materialismo histórico-dialético.

Para isso faremos um percurso de compreender os conceitos de tecnologia e razão técnica a partir da obra e autor citados e assim apresentar a proposta de política educacional dos institutos federais, a partir da legislação (Lei no 11.892/2008) e documento base (Um novo modelo em educação profissional e tecnológica: concepções e diretrizes), tendo em vista o conceito de politecnia e a articulação trabalho-ciência-tecnologia como 
elementos constituintes da proposta e analisar o papel destas instituições federais de ensino na perspectiva da oferta da formação tecnológica.

\section{A TECNOLOGIA E A RAZÃo TÉCNICA COMO EXPRESSÕES DA "NATUREZA" DO HOMEM}

Os termos tecnologia e tecnológico habitam nosso cotidiano de forma avassaladora, já faz bom tempo. Álvaro Vieira Pinto (2005) faz esse registro em sua obra ainda no início dos anos setenta do século passado.

Da mesma forma como este importante filósofo brasileiro afirmou o largo e indiscriminado emprego da palavra tecnologia naquele período, tal assertiva continua válida, assim como a imprecisão e ampla significação do uso do termo.

Vieira Pinto (2005) distingue quatro importantes significados para o conceito começando pelo aspecto etimológico e caracterizando-a como a epistemologia da técnica, onde a mesma,

na qualidade de ato produtivo, dá origem a considerações teóricas que justificam a instituição de um setor do conhecimento, tomando-a por objeto e sobre ela edificando as reflexões sugeridas pela consciência que reflete criticamente o estado do processo objetivo, chegando ao nível da teorização (PINTO, 2005, p. 220).

A tecnologia ainda, em seu significado mais usual e frequente, aparece como equivalente à técnica e, num terceiro significado, também como o conjunto de todas as técnicas presentes e utilizadas em uma determinada sociedade.

Um quarto significado se refere à ideologização da técnica por meio do desligamento de suas bases materiais, constituindo-se em processo de alienação e instrumento de dominação.

É no primeiro significado que balizaremos as principais reflexões deste ensaio com vistas a contribuir na compreensão da razão técnica como conceito indispensável à apreensão da natureza histórica e social do ser humano, sempre na perspectiva dialética.

Sem a compreensão dialética do processo da racionalidade, o desenvolvimento da tecnologia fica entregue a si mesmo, plana solto no espaço, sem história e sem raízes, e por isso sem razão suficiente. [...] A razão é o que a razão fez. Mas não sendo um ente anímico, imaterial, exige um sujeito 
que a tenha realizado, e este é o homem, e um modo pelo qual foi constituída, e este é a técnica (PINTO, 2005, p. 365).

A partir desse pressuposto integramos, por meio do enfoque materialista histórico-dialético, a centralidade do processo de produção social da existência humana na compreensão do conceito de tecnologia. $\mathrm{Na}$ gênese dessa reflexão encontraremos o trabalho, quer na sua dimensão ontológica, quer na sua dimensão histórica, onde "o homem vai se realizando na progressiva conquista do conhecimento e nas ações técnicas pelas quais efetua o domínio da natureza" (PINTO, 2005, p. 50). Portanto, "o fio condutor, só encontrado na relação original do homem com a natureza, isto é, em termos históricos, no processo da produção material da existência humana" (PINTO, 2005, p. 50) tem no trabalho o fundamento do conceito de tecnologia e consequentemente o caráter eminentemente técnico da ação humana.

É na práxis humana, sobretudo no pensamento que acompanha a ação que modifica as condições da existência humana, que podemos identificar o conceito de hominização apresentado por Álvaro Vieira Pinto. A técnica e a tecnologia são instrumentos de mediação no enfrentamento do ser humano na sua contradição natural com a natureza. É por meio desta produção filosófica que Vieira Pinto (2005) explicita a construção dos conceitos de técnica e de tecnologia e seus impactos na compreensão da realidade social e dos aspectos relacionados aos desiguais processos de desenvolvimento no sistema-mundo, sobretudo nas questões de dominação centro-periferia sob a égide do modo de produção capitalista.

É no processo de superação da contradição natural com a natureza, ou seja, na produção social e histórica pelo homem de sua existência que a técnica, ação humana, se apresenta como o modo de alcançar a referida superação. "A técnica não consiste, por conseguinte, num atributo dos atos vitais em geral, mas somente caracteriza aqueles que o homem executa em razão da condição existencial de produtor de si” (PINTO, 2005, p. 156).

Deve ser compreendida, portanto, em sua relação com a consciência, com a capacidade de projetar e assim, consequentemente e de forma 
dialética, a técnica tem relação direta com o trabalho em suas dimensões ontológica e histórica.

[...] a única definição possível da técnica consistirá em dizer que é o grau de consciência com que o homem representa para si relação entre os meios materiais ou ideais de que dispõe e emprega numa operação e as finalidades que deseja satisfazer pela aplicação desses meios. Claro está que o fundamento dessa relação repousa no conhecimento das propriedades do mundo objetivo, físico e social, o que significa ver na técnica um outro aspecto pelo qual se manifesta a capacidade humana de produzir, em geral (PINTO, 2005, p. 199-200).

Apreende-se, em síntese, numa perspectiva dialética de totalidade humana, onde o trabalho constitui um fenômeno ontológico e histórico da sociedade, que a tecnologia é função do estado de desenvolvimento deste fenômeno social e visa atender às exigências da produção e do desenvolvimento científico. Neste sentido, considerando a produção e o desenvolvimento científico em suas dimensões históricas e sociais, o desenvolvimento tecnológico compõe a totalidade do processo social, “expressão da base material objetiva que o desenrolar das forças produtivas, em dado momento, oferece, sob forma de configuração de fatos econômicos e de interesses políticos" (PINTO, 2005, p. 305). Daí a importância da compreensão dialética da tecnologia na realidade concreta da sociedade capitalista, sobretudo nas condições de subdesenvolvimento dos países periféricos submetidos à precarização das relações de trabalho e da dominação imperialista.

Finalmente, compreendemos em Vieira Pinto (2005) o conceito de razão técnica amparado na interpretação dialética da unidade dos contrários. 0 domínio da tecnologia expressa-se no domínio da razão, especificidade humana, que consubstancia o processo de hominização e da produção da existência por meio do trabalho (físico e intelectual).

Verifica-se, assim, poderem ser conciliados os dois pontos de vista, consistindo a verdade total na unidade deles, estabelecida pela dialética: tanto é possível julgar a sociedade dominada pela tecnologia, e neste caso a representação racional, a ideia, desempenha o papel de mediação, quanto entendê-la dominada pela razão, tendo a máquina, o método e a técnica por formas de mediação. A unidade de ambos os modos de compreensão realizase concretamente pela presença e ação do homem no mundo (PINTO, 2005, p. 373). 
Ainda, um aspecto importante na obra de Vieira Pinto (2005) trata da questão da essência e forma do trabalho, guardando relação com a discussão central da técnica/tecnologia. Apresenta uma dicotomia relativa entre essência e forma. A essência, em sentido absoluto, como a relação entre o homem e a natureza para a produção da subsistência, mas que assumirá diferentes condições relativas, históricas, nas formações sociais. A forma, em inumeráveis modalidades em que se distribui entre os membros da sociedade e que diz respeito não apenas às profissões diferenciadas em função da distribuição dos conhecimentos, mas igualmente aos materiais utilizados, aos instrumentos empregados e às técnicas fabricadoras conhecidas pelo grupo em cada fase, chamada civilização. A valoração do trabalho (e a diferenciação entre trabalho físico e intelectual) é outorgada pela sociedade, sendo uma arma ideológica na sociedade de classes.

As reflexões e conceitos aqui explicitados têm por objetivo pavimentar o caminho para as considerações seguintes do presente ensaio quanto à perspectiva emancipatória da Educação Tecnológica pretendida na proposta, concepção e diretrizes dos Institutos Federais no país.

Ainda que a discussão da educação profissional não seja objeto específico da produção teórica de Álvaro Vieira Pinto aqui referenciada ( $O$ Conceito de Tecnologia, Volume I), a perspectiva da formação crítica dos técnicos, tendo por horizonte a politecnia, está presente na obra, permitindonos algumas inferências.

\section{A ARTICULAÇÃO TRABALHO-CIÊNCIA-TECNOLOGIA-CULTURA NA PROPOSTA EDUCACIONAL DOS INSTITUTOS FEDERAIS}

Os Institutos Federais compõem a Rede Federal de Educação Profissional, Científica e Tecnológica (Rede), instituída pela Lei Federal $n^{\circ}$ 11.892, de 29 de dezembro de 2008, por iniciativa do Presidente Luiz Inácio Lula da Silva.

Conforme determina o artigo $2^{\circ}$ da Lei $\mathrm{n}^{\circ} 11.892 / 2008$,

os institutos federais são instituições de educação superior, básica e profissional, pluricurriculares e multicampi, especializados na oferta de educação profissional e tecnológica nas diferentes modalidades de ensino, 
com base na conjugação de conhecimentos técnicos e tecnológicos com as suas práticas pedagógicas (BRASIL, 2008).

Para além deste marco normativo-legal, a criação dos institutos federais é resultado de um processo histórico e significou um marco na trajetória da educação profissional no Brasil, por meio de um modelo institucional inovador na sua proposto pedagógica e um conceito de educação profissional e tecnológica sem similar em outros países (PACHECO, 2011). Para situar este marco histórico faz-se necessário compreender a educação profissional enquanto campo em disputa de projetos educacionais e de sociedade no Brasil, ao longo de mais de cem anos.

A concepção hegemônica, predominante por mais de um século, voltada ao capital se expressou na criação das Escolas de Aprendizes Artífices em 1909, nos processos das sucessivas reformas - como a Capanema (anos 1940) - e nas Leis de Diretrizes e Bases da Educação Nacional (1961, 1971 e 1996), que traduzem ora o caráter moral-assistencialista, ora "uma concepção de caráter funcionalista, estreito e restrito apenas a atender aos objetivos determinados pelo capital, no que diz respeito ao seu interesse por mão de obra qualificada" (BRASIL, 2010, p. 19-20).

Em contraposição aos projetos voltados ao mercado de trabalho/capital, a educação profissional também é marcada por discussões e experiências que se situam no campo da resistência ao modo de produção de vida existente.

Fruto do processo histórico de disputas políticas e do conjunto de correlações de forças que marcam uma importante mudança de rumo no governo federal no início do século XXI, a Rede Federal de Educação Profissional, Científica e Tecnológica nasce da confluência de alguns esforços e experiências no interior do próprio conjunto de instituições federais de educação profissional (escolas técnicas e agrotécnicas, escolas vinculadas às universidades e CEFET's) e, sobretudo, da clara reorientação das políticas públicas federais, especialmente no campo educacional, que promoveu forte inflexão à implementação dos ajustes neoliberais no ordenamento jurídico, 
político e institucional da educação nacional do período anterior (MADUREIRA, 2018).

O próprio documento orientador da concepção e diretrizes dos institutos federais relata esta mudança, registrando que

Cumpre destacar que, a partir do ano de 2003, a política do governo federal já apontava em outra direção. Essas instituições federais, situadas por todo o território nacional, historicamente voltadas para a educação profissional e para o desenvolvimento econômico, criadas e mantidas com verbas públicas federais, defrontam-se com uma política de governo que traz em essência uma responsabilidade social - tradução das forças sociais que representa - como fio condutor de suas ações (BRASIL, 2010, p. 14).

Neste sentido,

O foco dos institutos federais é a promoção da justiça social, da equidade, do desenvolvimento sustentável com vistas à inclusão social, bem como a busca de soluções técnicas e geração de novas tecnologias. Estas instituições devem responder, de forma ágil e eficaz, às demandas crescentes de formação profissional, por difusão de conhecimentos científicos e de suporte aos arranjos produtivos locais (SILVA, 2009 apud MADUREIRA, 2018).

Tal afirmação permite compreender a Rede e os institutos federais como institucionalização definitiva da educação profissional e tecnológica como uma política pública articulada a um projeto de nação de concepção progressista, "que entende a educação como compromisso de transformação e enriquecimento de conhecimentos objetivos capazes de modificar a vida social e atribuir-lhe maior sentido e alcance no conjunto da experiência humana" (BRASIL, 2010, p. 18).

A concepção de educação apresentada materializar-se-á nos projetos pedagógicos implementados em cada ação institucional (cursos, projetos, etc.), que se pautam por diretrizes, pelos princípios e pelas finalidades dos institutos federais, explicitados no próprio texto da Lei $\mathrm{n}^{\circ} 11.892 / 2008$.

A indissociabilidade do ensino, da pesquisa e da extensão, dimensões estas presentes nos institutos federais, fortalece a atuação institucional desde a educação básica até a pós-graduação. Dessa forma, a pesquisa articula os princípios científicos e educativos com vistas a possibilitar o desenvolvimento da capacidade do educando de gerar conhecimento, assim como a extensão promove o diálogo concreto com a realidade e o conjunto da sociedade. 
Educação, trabalho, ciência e tecnologia articulam-se nas propostas pedagógicas e no cotidiano escolar dos institutos federais, na perspectiva de uma educação omnilateral entendida como uma "concepção de educação ou de formação humana que busca levar em conta todas as dimensões que constituem a especificidade do ser humano e as condições objetivas e subjetivas reais para seu pleno desenvolvimento histórico" (FRIGOTTO, 2012, p. 265). Daí depreende-se que a formação cidadã e integral, com vistas a garantir aos educandos as condições de interpretar a realidade e poder transformá-la, ideário comum que caracteriza os institutos federais enquanto rede social, deve prevalecer sobre o caráter meramente utilitarista do conhecimento técnico. Neste sentido, "a partir do entendimento de que o conhecimento é um dos elementos constituintes da cidadania, a reflexão acerca do sentido e da dimensão dos saberes que circula na rede social passa, necessariamente, pelo seu direito de acesso a eles" (BRASIL, 2010, p. 25).

Democratização do acesso e inclusão, elementos indispensáveis à compreensão da educação como um bem social, estão presentes de forma visceral nos institutos federais e são determinantes para o cumprimento do papel estratégico da Rede, quer na contribuição do desenvolvimento nacional, quer no inadiável processo de inserção cidadã de milhões de brasileiros historicamente alijados da cidadania plena e do protagonismo da transformação social.

Isto significa situar a educação profissional, considerando as bases histórico-materiais em que essa concepção de educação se constrói, à luz da politecnia, ou seja, o domínio dos fundamentos científicos das diferentes técnicas que caracterizam o processo de trabalho moderno (FRIGOTTO, 2012b apud MADUREIRA, 2018). Aos institutos federais, portanto, dadas as suas características e sua trajetória de criação, assim como seus objetivos e finalidades, não é possível ignorar esta dimensão, mas sim incorporá-la integralmente, articulando-a ao conjunto de diretrizes e ações de uma instituição pública de ensino identificada com um projeto de inclusão social e com um projeto de Nação por meio da Educação Profissional e Tecnológica. Dessa forma, "ao se constituírem enquanto rede social, [os institutos] 
dialogam com os sujeitos que constroem a realidade socioeconômicocultural brasileira para construir formas próprias de educação que respondam às demandas de grupos sociais" (BRASIL, 2010, p. 39).

\section{A FORMAÇÃO TECNOLÓGICA E SEU POTENCIAL REVOLUCIONÁRIO NOS INSTITUTOS FEDERAIS: A “CONSCIÊNCIA PARA SI” EM ÁlVARO VIEIRA PINTO}

Por se basear no pensamento dialético, a obra de Álvaro Vieira Pinto no processo de "arquitetura" da filosofia da técnica teorizada, em nenhum momento negligencia a interpretação da totalidade, sobretudo na análise da realidade social, especialmente das condições de dependência do país (econômica, política e tecnológica).

Ao contrário, a cada momento o autor traz a reflexão sobre o necessário processo de suplantar o subdesenvolvimento por meio, também (inclui a luta política e social), do que vai chamar de consciência para si, tendo por síntese a superação da alienação e da dominação a partir da capacidade da classe trabalhadora perceber a realidade e conceber autonomamente o projeto de transformá-la em seu favor (PINTO, 2005).

Situamos aí um importante ponto de encontro do pensamento de Álvaro Vieira Pinto com a concepção e diretrizes dos institutos federais, cuja categoria central de análise repousa na dimensão histórica do processo de trabalho contemporâneo, ou seja, "isto representa tomar o trabalho como princípio educativo e como categoria orientadora das políticas de educação profissional e tecnológica" (BRASIL, 2010, p. 32).

Importante registrar a afirmação de Vieira Pinto (2005) há quase 50 anos: "a formação tecnológica das novas gerações do país atrasado tem importância capital porque se trata de engendrar um potencial de natureza revolucionária" (PINTO, 2005, p. 387). Alerta ainda o autor: "é cioso afirmar a urgência da difusão das escolas técnicas para toda a massa trabalhadora. Mas será preciso mudar radicalmente o espírito segundo o qual se desenrola a prática dessa instrução" (ibid, p. 336). 
Neste sentido, entendemos o papel dos institutos federais enquanto estratégia de ação política e de transformação social explicitada em seu documento base (BRASIL, 2010).

A consciência para si decorre da compreensão da realidade na perspectiva da transformação política, econômica, cultural e social. A educação profissional e tecnológica nesta direção toma o homem como referência fundamental e a técnica como ação humana, assim como a tecnologia "o estudo do processo de criação do homem pela práxis da realização existencial material de si, em função de seus condicionamentos sociais" (PINTO, 2005, p. 246).

Situamos também na perspectiva de consciência para si o fundamento da politecnia, definida anteriormente, como concepção da formação profissional nos institutos federais, destacando-se o domínio integrado de conhecimentos científicos, tecnológicos e sócio históricos (BRASIL, 2010).

[...] Galgando a compreensão unitária da técnica, na plena universalidade, em função de novas condições sociais em que a exercer, passará a dominar a que executa e todas as demais, sabendo o que significa, quanto vale e quais as finalidades dela, em vez de ser, como agora, dominado por ela, a ponto de receber do trabalho particular, profissional, sua qualificação social enquanto ser humano. 0 domínio teórico da técnica pelo homem liberta-o da servidão prática à técnica [...] (PINTO, 2005, p. 223).

Aliado à concepção de politecnia, a pesquisa como princípio educativo e científico caracteriza a concepção e diretrizes dos institutos federais na perspectiva de uma formação emancipatória, integral. Da mesma forma, Álvaro Vieira Pinto (2005) explicita a necessidade de criação pelo país de sua tecnologia, de sua ciência com função de instrumento de libertação.

[...] Instauradas as condições iniciais, daí por diante só deve ser admitida a política de estímulo à criação científica e tecnológica autóctone, voltada para a solução dos problemas nacionais concretos, e de rápido desligamento de qualquer dependência, inclusive no campo da produção teórica (PINTO, 2005, p. 277).

Em síntese, a formação tecnológica na perspectiva da concepção e diretrizes dos institutos federais encerra um potencial revolucionário no que Vieira Pinto denomina de consciência para si,

[...]"não porque a "tecnologia" em si mesma, por virtude imanente, seja a criadora do salto revolucionário, mas porque oferece um fundamento antes 
inexistente para a constituição da consciência para si do colonizado, cuja primeira manifestação consiste em fazê-lo ver-se como tal. [...] (PINTO, 2005, p. 272).

\section{CONSIDERAÇõES FINAIS}

À guisa de consolidação da base teórico-metodológica adotada queremos enfatizar a presença de categorias fundamentais da perspectiva dialética nas reflexões de Álvaro Vieira Pinto abordadas na temática central do presente ensaio.

Rebatendo a concepção de linearidade, a categoria da contradição explicita o processo histórico e social do progresso tecnológico (da tecnologia) caracterizado pela sua relação com o trabalho, também social e histórico, portanto, expressão do desenvolvimento das forças produtivas em cada momento, de forma desigual e marcada tanto pela alienação quanto pela própria exploração do homem pelo homem.

Sendo o homem mediador das relações sociais, portanto agente/sujeito da intervenção na realidade, à técnica/tecnologia, enquanto ação humana, podemos também atribuir este caráter (mediação). De modo similar a categoria reprodução se faz presente na percepção do controle e do domínio da tecnologia na perspectiva da manutenção do modo de produção capitalista.

A categoria totalidade, por meio da conexão entre as especificidades das reflexões sobre o conceito de tecnologia e o contexto social mais amplo (que produz as contradições), está presente ao longo de toda a obra de Álvaro Vieira Pinto distinguindo o que o próprio autor denomina de pensamento crítico, em oposição a concepções idealistas, metafísicas e/ou ingênuas.

Procuramos apresentar neste breve ensaio que na proposta de educação tecnológica contida no documento base que estabeleceu a concepção e diretrizes da Rede Federal de Educação Profissional, Científica e Tecnológica identifica-se potencial de natureza revolucionária na perspectiva da contribuição deste modelo de formação no que Álvaro Vieira Pinto denomina de "consciência para si", entendo-a como consciência crítica da classe trabalhadora em luta pela ascensão histórica, pela superação da 
condição de dependência e exploração, integrando-a contudo na totalidade da indispensável luta social e política em todas as suas dimensões, sobretudo as contradições fundamentais de uma sociedade dividida em classes.

\section{Referências}

BRASIL. Lei n. 11.892, de 29 de dezembro de 2008. Institui a Rede Federal de Educação Profissional, Científica e Tecnológica, cria os Institutos Federais de Educação, Ciência e Tecnologia, e dá outras providências. Brasília, 2008. Disponível em:<http://www.planalto.gov.br/ccivil_03/_Ato20072010/2008/Lei/L11892.htm>. Acesso em: 15 ago. 2020.

Ministério da Educação. Instituto federal de educação, ciência e tecnologia: um novo modelo em educação profissional e tecnológica: concepção e diretrizes. Brasília, 2010. Disponível em:<http://www.portal.mec.gov.br/index.php?option=com_docman\&view =download\&alias=6691-if-concepcaoediretrizes\&category_slug=setembro2010-pdf\&Itemid=30192. Acesso em: 15 ago. 2020.

FRIGOTTO, G. Educação omnilateral. In: CALDART, R. S. et al. Dicionário da educação do campo. Rio de Janeiro: Escola Politécnica de Saúde Joaquim Venâncio; São Paulo: Expressão Popular, 2012.

MADUREIRA, J. C. B. O PRONERA e a garantia do direito à educação: a experiência do Curso Superior de Tecnologia em Agroecologia no Assentamento Contestado (Lapa, PR). 2018. 90 f. Dissertação (MagísterenGobierno y Gestión de Políticas Públicas) - FLACSO/FPA, 2018.

PACHECO, E. Institutos federais: uma revolução na educação profissional e tecnológica. In: PACHECO, E. (Org.) Institutos federais: uma revolução na educação profissional e tecnológica. São Paulo: Moderna, 2011.

PINTO, A. V. 0 conceito de tecnologia. V. 1. Rio de Janeiro: Contraponto, 2005. 